\title{
Da prosa poética aos textos de opinião: \\ a questão da identidade em Mia Couto
}

Avani Souza Silva ${ }^{1}$

\begin{abstract}
RESUMO: A questão da identidade permeia não somente a obra poética de Mia Couto, mas também seus textos de intervenção político-social. A partir da categorização de contos e crônicas do escritor, referenciais para os textos jornalísticos, e utilizando as noções de identidade e descentramento do sujeito, formuladas por Stuart Hall, enfocaremos a questão da identidade nos textos jornalísticos do escritor.
\end{abstract}

ABSTRACT: The identity issue underlies not only Mia Couto's poetic work, but also his texts of political-social intervention. Starting from the categorization of his short stories and chronicles, which are referential for journalistic texts, and by using notions of identity and decentralization of the subject as formulated by Stuart Hall, we focus on the identity matter presented in Couto's journalistic texts.

PALAVRAS-CHAVES: Identidade; descentramento; conto; crônica; Mia Couto KEYWORDS: Identity; decentralization; short story; chronicle; Mia Couto

Mia Couto publicou diversos livros de contos: Cronicando, Cada homem é uma raça, Vozes anoitecidas, Na berma de nenhuma estrada, Estórias abensonhadas, O fio das missangas, Contos do nascer da terra. Como esses contos têm estreita ligação com a crônica, vamos primeiramente falar sobre esses gêneros narrativos que marcam a obra do escritor e que, de certa forma, seja pela temática ou por estórias contadas, são referenciados nos seus textos de opinião.

$\mathrm{O}$ escritor moçambicano começou sua carreira publicando pequenas crônicas em uma coluna chamada "Quotidiano", do jornal Notícias, de Maputo, nos anos 1980. Posteriormente à publicação de Vozes anoitecidas, em 1987, suas primeiras crônicas em jornal foram reunidas e publicadas no livro $O$ desanoitecer da palavra, de Fernanda

\footnotetext{
1 Doutoranda em Estudos Comparados das Literaturas dos Países de Língua Portuguesa pela FFLCH/USP.
} 
Angius e Matteo Angius. Sem dúvida, é a primeira publicação que vem a lume sobre os escritos de Mia Couto.

Mia Couto apresenta uma particularidade na maneira como escreve os seus contos. Eles se assemelham muito a crônicas, seja na extensão, na temática, sendo por essa razão um gênero misto, considerado, portanto, híbrido, pois reúne gêneros diferentes.

Segundo Jorge de Sá (1999), contrariamente ao conto, que tem uma densidade específica centrada na exemplaridade de um instante da condição humana, a crônica tem apenas registros circunstanciais feitos por um narrador-repórter. Lembra ainda que, enquanto no conto o autor mergulha profundamente na construção do tempo, do espaço, das personagens e principalmente da atmosfera daquilo que será contado, e como será contado, o cronista, por sua vez, desliza superficialmente sobre seus próprios comentários sem ter a preocupação de encarnar a figura do narrador. A crônica, por isso, é breve, rápida, tem uma vida relativamente curta, pois o próprio suporte que a veicula tem esse caráter de transitoriedade, de brevidade, de urgência.

Uma crônica de jornal lida é uma crônica esquecida, ela não tem permanência, pois ela tem urgência em ser escrita, urgência em ser lida. Entretanto, um fato qualquer da vida que poderia passar despercebido é recuperado por ela e ganha contornos literários nas mãos de um cronista. Mas tudo isso não tira o seu caráter de brevidade, circunstancialidade, emergência e pouca durabilidade, o que não impede que sua permanência seja aumentada quando são reunidas em livro, por exemplo. E tampouco a simples mudança de suporte não implica necessariamente maior visibilidade ao cronista e permanência da crônica.

Carlos Reis (2000) argumenta que a crônica não é um gênero estritamente literário, daí a sua dificuldade em defini-la. Do ponto de vista da narratologia, o que importa é uma tentativa de definição e, neste sentido, as propriedades inerentes à crônica estariam mais ligadas à sua temporalidade. Reis privilegia duas grandes 
acepções da crônica: como relato historiográfico medieval e como texto de imprensa. Enquanto aquela se preocupava em destacar um herói, esta abordava um fato do quotidiano, realçando fatores sociais, culturais, históricos etc. que, à primeira vista, poderiam passar despercebidos ao observador. A crônica teria nascido influenciada por outras estratégias discursivas, principalmente o folhetim, do qual herdou a regularidade, um tom por vezes lúdico, e um certo pendor ensaístico, pondera Carlos Reis, lembrando também que a crônica herdou da epistolografia o tom de diálogo, de conversa, às vezes de carta para um destinatário quase familiar. A crônica tem, portanto, um estatuto próprio como gênero narrativo, em que se salienta a brevidade de sua extensão, mas principalmente a marcação de sua temporalidade.

Ainda segundo Carlos Reis ${ }^{2}$, o conto relaciona-se matricialmente com as formas simples, postuladas por André Jolles. Essas formas simples, que incluem contos, legendas, sagas, lendas, mitos, adivinhas, ditados, casos e chistes, permanecem ao longo do tempo, recontadas ad infinitum, sem perder nunca sua forma, que é popular, e não tem autoria, mas tem permanência. Para Jolles (1996), é necessário o ingrediente do maravilhoso para dar a essas formas a atemporalidade, a não espacialidade e a imprecisão histórica. Assim, o conto estaria relacionado às formas simples e ao maravilhoso. A forma artística, elaborada e que para Jolles é a novela, seria o conto literário como o conhecemos.

Segundo Cortázar (1993), existem certas constantes que se aplicam a todos os contos. Não há temas bons ou ruins, e sim tratamento bom ou ruim dos temas. Para ele, o tempo e o espaço do conto têm de estar condensados, submetidos à alta pressão espiritual de forma a promover uma "abertura", a exemplo do que ocorre com uma câmera fotográfica que limita espacialmente a imagem fotografada, mas amplia a visão de quem a vê. Ou seja, o fotógrafo escolhe um

\footnotetext{
${ }^{2}$ REIS, Carlos. Anotações do curso regular "Teoria e análise do conto: fronteiras, passagens e derivas", ministrado na FFLCH/USP, em outubro/novembro de 2004, a convite do curso de pós-graduação da área de Estudos Comparados de Literaturas de Língua Portuguesa.
} 
enquadramento, um limite que possa atuar o espectador como uma abertura para além do argumento visual da foto. Como o tempo e o espaço têm de estar condensados, um conto não tem elementos gratuitos, decorativos e não age cumulativamente como uma novela, já que não tem o tempo como seu aliado.

O conto para Cortázar é um gênero de dificil definição. Não obstante, ele trabalha com três noções para definir sua estrutura: as noções de significação, de intensidade e de tensão. O elemento significativo do conto reside no tema; a intensidade é a eliminação de todo o aparato literário que pode ser explorado em uma novela, que tem uma extensão maior, e não em um conto que é comprimido. Assim, a novela estaria para a expansão enquanto o conto para a compressão. E a tensão, por fim, é a intensidade que se exerce na maneira como o autor vai aproximando o leitor, pouco a pouco, daquilo que é contado. Um bom conto reúne essas três noções.

Ainda que exista uma especulação a respeito da extensão do conto, e tentativas de quantificação dessa extensão, sabidamente o conto é de extensão menor que o da novela, isso é um consenso entre os estudiosos desse gênero narrativo. Mas não existe um limite mínimo previsto de extensão para o conto, tanto que na contemporaneidade há os micro-contos.

Para Carlos Reis, o princípio da concentração de que fala Julio Cortázar é que determina as demais propriedades do conto: a) reduzido número de personagens; essas personagens são construídas com tipos humanos, sem complexidade do ponto de vista psicológico, e às vezes se confundem com o espaço; b) o espaço é pequeno e limitado; c) as ações são simples e muitas vezes apontam para um desenlace previsível.

Mia Couto, por sua vez, define o conto aproximando-o da crônica, como a conhecemos:

Não existem fórmulas feitas para imaginar e escrever um conto. O meu segredo (e que vale só para mim) é deixarme maravilhar por histórias que escuto, por personagens com quem me cruzo e deixar-me invadir por pequenos detalhes da vida quotidiana. (...) O conto é feito com pinceladas. É um quadro sem moldura, o início 
inacabado de uma história que nunca termina. O conto não segue vidas inteiras. É uma iluminação súbita sobre essas vidas. Um instante, um relâmpago. (COUTO, 2005, p. 46)

Neste artigo, embora buscando nos deter nos textos não literários do escritor, uma passagem pela crônica e pelo conto será interessante porque além de ser esse o percurso de escrita adotado inicialmente pelo escritor, a que ele ocasionalmente volta, esses gêneros vão fornecer recursos estilísticos para a elaboração dos seus textos de opinião. Esses textos terão também um aspecto híbrido, às vezes utilizando a estrutura da crônica, principalmente quando conta estórias. Além da referência aos gêneros conto e crônica, o texto de opinião do escritor ainda utiliza recursos da epistolografia de onde herda o tom de diálogo.

A maioria dos contos do escritor dá-nos um retrato da vida urbana e rural de Moçambique, dos costumes, dos aspectos religiosos, do sagrado, do mítico, do transcendente, da memória e da ancestralidade, utilizando às vezes o gênero estranho de que nos fala Todorov (1975). No entanto, e essa é uma característica do escritor, como já foi dito, há um hibridismo na sua escrita, pois ele reúne os aspectos do conto aos da crônica, formando uma prosa poética das mais singulares.

Embora em alguns contos haja um hibridismo com o gênero crônica, a estrutura do conto é a que mais sobressai de todos os textos já publicados. Já no livro $O$ pais do queixa andar, o escritor assume uma voz de cronista, relatando diversos casos ocorridos em Maputo, fazendo uma espécie de raio $\mathrm{X}$ da sociedade local, tecendo suas críticas e avaliando o comportamento das pessoas, colocando o leitor frente a frente com o seu país, através da lente do narrador-cronista. O escritor também aponta nessas crônicas uma das consequências da globalização, ou seja, a difusão do consumismo, seja como realidade, seja como sonho, que contribui para o efeito de "supermercado cultural", um dos efeitos da "homogeneização cultural". (HALL, 2006, p. 75). 
Também é marcadamente de crônicas o livro do escritor recentemente publicado, Pensageiro frequente, reunindo textos publicados na revista de bordo Índico, da companhia área LAM Linhas Aéreas de Moçambique. Esse novo livro traz alguns contos curtos, mas é essencialmente de crônicas. A propósito desse livro, que teve um pré-lançamento em Lisboa, antes mesmo do livro sair do prelo, Mia Couto relata em entrevista a um site português que, como tem medo de avião, passava o tempo da viagem escrevendo para outras pessoas que como ele também tinha medo de voar. Esses textos depois foram publicados na revista de bordo da companhia aérea, e agora estão reunidos em livro. Confirma-se, perfeitamente, a finalidade de uma crônica, sua atualidade, e a circunstancialidade de sua temática, diferentemente do conto.

Tema recorrente e muito atual que se coloca para Mia Couto é o das identidades, sempre tratado no seu texto poético, e principalmente nos romances Um rio chamado tempo, uma casa chamada terra, em que o escritor coloca como tema central a busca da identidade, denunciando a fragmentação cultural e desagregação encontrada por Mariano em sua ilha natal; ou em Terra sonâmbula em que retrata a busca e reconstrução da identidade do povo solapada pela guerra. A identidade já é tema de seu primeiro livro, Raiz de orvalho: "Preciso ser um outro para ser eu mesmo" (versos do poema "Identidade").

Confrontando sempre tradição e modernidade, velho e novo, rural e urbano, Mia Couto esclarece a questão da identidade que emerge nessas dualidades e tensões presentes em sua matéria literária:

É preciso fazer um bocadinho o caminho com duas pernas: tem que ter um pé na tradição e outro pé na modernidade. Só assim se chega a um retrato capaz de respeitar as dinâmicas e as relações complexas do corpo moçambicano. A chamada "identidade moçambicana" só existe na sua própria construção. Ela nasce do entrosamento, de trocas e destrocas. (MAQUEA, 2005, p. 208)

Se a questão da identidade é um problema presente nas obras de Mia Couto, não menos presente é essa questão em sua própria vida de 
intelectual e escritor profundamente engajado com as questões de seu tempo. Ele sempre discorreu, em várias entrevistas ou palestras, sobre a questão das identidades que o habitam, que habitam seus textos, que habitam o homem de maneira geral. Para ele, o homem não é apenas a sua própria identidade como expressão de sua individualidade, se não diversas identidades, diversos modos de ser e de estar no mundo. Não é por outra razão que denomina sua nacionalidade "moçambicanos", no plural, e não moçambicano, no singular, devido mesmo à existência de diversos Moçambiques, indicando as diversas identidades de seu povo.

Em entrevista a Marilene Felinto ${ }^{3}$, Mia Couto, inquirido sobre como é ser escritor, responde que não é escritor, e sim está escritor, dando inclusive ao status de escritor um caráter provisório, como provisórias são todas as identidades. A identidade, portanto, não seria, do ponto de vista do escritor, um estado definitivo e indelével do homem, mas sim um estado plural e transitório que reúne múltiplas e variadas identidades. Dentro dessa ótica, faz sentido, portanto, a expressão "estar escritor" e não "ser escritor", pois subjaz desta afirmativa todo um contexto ideológico que permeia o discurso de Mia Couto que é o das múltiplas e móveis identidades.

Um aspecto também muito interessante que Mia Couto relata em suas interlocuções, e aqui eu cito a palestra proferida no Sesc/Vila Mariana ${ }^{4}$, em São Paulo, é a capacidade que as pessoas têm de pensá-1o como negro, por ser africano, e como mulher, por ter o nome Mia, reproduzindo estereótipos sobre as identidades. Nessa palestra, o escritor relata que certa vez, acompanhando, como editor do jornal Noticias de Maputo, o Presidente de Moçambique, Samora Machel, a uma viagem a Cuba, foi homenageado pelo governo cubano com um colar feminino de presente. Naturalmente, o cerimonial do governo, sem até então conhecer Mia Couto, imaginou que ele fosse uma mulher.

\footnotetext{
3 Disponivel em

http://www.macua.org/miacouto/MiaCoutoexerciciodahumildade.htm

${ }^{4}$ Palestra proferida em 06.06.06, por ocasião do lançamento do romance O outro pé da sereia.
} 
Esse é um exemplo que o escritor cita para enumerar a identidade plural, as identidades que uma pessoa pode ter.

Outro exemplo citado pelo escritor: ter sido anunciado, ao ingressar no recinto onde daria uma palestra, numa universidade europeia, como "Sra. Mia Couto". Quando ele entrou foram muitas as risadas. Há inúmeros exemplos citados pelo autor, sempre confundido com uma mulher pela singularidade do nome, e com um homem negro, pelo fato de ser africano, devido aos estereótipos que habitam o imaginário europeu e americano. Esses exemplos todos, para Mia Couto, revelam as fronteiras permeáveis das identidades.

Livro emblemático do tema das identidades para Mia Couto é Cada homem é uma raça. Depois o escritor ampliou esse conceito para “cada homem é uma nação”. (COUTO, 2005, p. 96). Há alguns contos nesse livro em que o escritor coloca em posição central a questão da identidade, a começar pelo título que amplia a noção de raça como grupo étnico, passando a ser diversas e infinitas etnicidades correspondentes a cada indivíduo. Assim, se cada homem é uma raça, uma etnia, e sendo a etnia um fator de identidade, portanto as identidades passam a ser múltiplas, pois abarcam não apenas o conjunto étnico, mas cada elemento distinto de todos os conjuntos que compõem a universalidade.

Como dissemos, a questão da identidade permeia toda a obra de Mia Couto. Focamos especificamente esse tema nos textos de opinião do escritor que são os textos dissertativos, não literários, que ele escreveu para palestras, sites, jornais, apresentações várias, em que discorre sobre diversos assuntos da ordem do dia, desde a questão africana, à questão política puramente moçambicana, à guerra, multiculturalidade, costumes etc., e inclusive sobre a eleição de Obama, texto inicialmente publicado na internet e que depois deu título ao livro de intervenções $E$ se Obama fosse africano?

Para Stuart Hall, as identidades culturais são aqueles aspectos identitários que surgem do pertencimento a culturas étnicas, raciais, e acima de tudo nacionais, ou seja, aos fenômenos estáveis. Ser 
argentino, católico, negro, maconde, por exemplo, são aspectos identitários. Para Hall, a crise de identidade do sujeito surge quando os fenômenos sociais estáveis entram em declínio. Para o estudo das identidades, Hall aponta três concepções muito diferentes de identidades: do sujeito do Iluminismo, do sujeito sociológico e do sujeito pós-moderno. Por uma questão metodológica, definimos as identidades conceituadas para percebermos a noção do sujeito pós-moderno, de identidade móvel, a que se refere Mia Couto nos seus textos de opinião:

A concepção do sujeito do Iluminismo está baseada no sujeito como sendo totalmente centrado, cujo centro está enraizado na interioridade que surge com o nascimento da pessoa e se desenvolve ao longo de sua vida, enquanto sua essência permanece a mesma. O sujeito do Iluminismo era descrito como masculino. (HALL, 2006, p. 10)

O sujeito sociológico seria o resultado da crescente complexidade do mundo moderno, em que cresce também a consciência de que o núcleo do sujeito não é autônomo e auto-suficiente, mas é formado pela interação com outras pessoas que mediavam para o sujeito valores, sentidos e símbolos, isto é, a cultura. Nesta concepção, a identidade é constituída de interação entre o eu a sociedade num diálogo contínuo com os mundos culturais e as identidades que esses mundos oferecem. $\mathrm{O}$ eu é modificado a partir dos mundos culturais exteriores com os quais interage. No sujeito sociológico já aparece a noção masculino e feminino. (HALL, 2006, p. 11)

Já o sujeito pós-moderno surge em decorrência do processo de mudanças nos mundos culturais, e se caracteriza pela não fixidez de sua identidade, continuamente transformada em relação aos mundos culturais que o rodeiam. (HALL, 2006, p. 13)

Segundo Stuart Hall, o sujeito, previamente vivido como tendo uma identidade unificada e estável, está se tornando fragmentado; composto não de uma única, mas de várias identidades, algumas vezes contraditórias ou não-resolvidas. A identidade torna-se uma "celebração móvel": formada e transformada continuamente em relação às formas pelas quais somos representados ou interpelados nos sistemas culturais que nos rodeiam. Esse processo produz o sujeito pósmoderno, conceituado como não tendo uma identidade fixa, essencial ou permanente. Assim, dentro do individuo há identidades contraditórias, empurrando em diferentes direções, de tal modo que as 
identificações estão sendo continuamente deslocadas. A identidade plenamente unificada, para Stuart Hall, é uma fantasia.

Uma das questões que deslocam as identidades é a globalização, entendida como aqueles processos atuantes em escala global, que atravessam fronteiras nacionais, integrando e conectando comunidades e organizações em novas combinações de espaço-tempo, tornando o mundo, em realidade e experiência, mais interconectado. Diminuem-se as distâncias, e fatos que ocorrem em determinados lugares causam impacto imediato sobre pessoas e lugares situados a uma grande distância. A globalização como fenômeno de interconexão está deslocando as identidades culturais nacionais. A globalização é, portanto, um fenômeno que faz circular não só os diversos bens agrícolas, técnicos e industriais, mas também os produtos culturais, os quais exercem grande influência no comportamento e modo de ser das pessoas. A crítica à massificação provocada pela globalização também estará presente nas obras do escritor moçambicano.

Para Stuart Hall, a globalização não vai simplesmente destruir as identidades nacionais, mas sim provocar a emergência de novas identificações globais e novas identificações locais. Identificações é o termo mais apropriado, sugerido por Hall, para as identidades em processo, em movimento, já que elas não são estáticas.

Hall descreve as consequências da globalização sobre as identidades culturais, sintetizando-as em três momentos: a desintegração das identidades nacionais em razão da homogeneização cultural (consequência da globalização); o reforço das identidades nacionais como resistência à globalização; e o declínio das identidades nacionais dando lugar às novas identidades - híbridas. A desintegração das identidades nacionais dá-se pelo confronto com outras identidades. O estudioso pergunta, a título de exemplo, como ser europeu num continente colorido com diversas outras etnias, não só provenientes de antigas colônias, mas também de outros continentes? Quanto ao fortalecimento de identidades locais ele pode ser visto com uma reação defensiva contra a presença de outras culturas. E 
finalmente a produção de novas identidades é proveniente dos fenômenos sociais do hibridismo, mistura de culturas.

Essas novas identidades que abarcam múltiplas identidades, já que a identidade não é única e nem estática, são as que Mia Couto se refere como fenômeno da mestiçagem. E muitas de suas estórias e de seus personagens vão justamente sintetizar esses fenômenos, como é o caso, por exemplo, dos contos "Sidney Poitier na barbearia de Firipe Beruberu", de Cada homem é uma raça, e "Sangue da avó, manchando a alcatifa", de Cronicando.

Em Pensatempos, Mia Couto no texto "A fronteira da cultura" fala sobre os produtos tipicamente africanos, mas que foram trazidos da China ou da América Latina e apropriados pela cultura moçambicana, passando a ser moçambicanos também, demonstrando o hibridismo cultural. O autor discute a identidade móvel de que nos fala Stuart Hall no texto "Uma cidadania à procura da sua cidade":

A nossa própria ideia sobre quem somos foi sendo alterada. Nas décadas de 70 e 80 a nossa identidade era simples e homogênea: éramos moçambicanos. E ponto final. Não era pensável, nesse momento, concebermo-nos como macuas, macondes, pretos, mulatos, brancos. De um modo geral, para todos nós, a primeira coisa da nossa identidade é ainda o sermos moçambicanos. Hoje em dia, porém, outras formas de pertença estão-se esboçando. Para muitos de nós estão nascendo outras primeiras identidades. Pode ser uma identidade racial, tribal, religiosa. Esse sentimento de pertença pode colidir com isso que chamamos de "moçambicanidade". Pensar que me alio a alguém porque somos da mesma raça não é apenas errado mas é historicamente pouco produtivo. (2005, p. 87)

No livro E se Obama fosse africano? e outras interinvenções, Mia Couto aborda diversos assuntos da ordem do dia, desde textos sobre Guimarães Rosa, Jorge Amado, Ibsen, Craveirinha e Henri Junod, temas de escrita e oralidade, até a famosa oração da sapiência intitulada "Os sete sapatos sujos" que o popularizou na internet. No texto "O futuro por metade" Mia Couto toca no assunto da resistência à identidade de gênero como identidade nacional, mesmo que temporária. 
Relata o escritor uma experiência como jornalista, em 1975, ao cobrir as comemorações do Dia da Mulher Moçambicana, no porto de Maputo:

Quem dirigia o encontro era o saudoso general Sebastião Mabote. Logo no início do encontro cantaramse e clamaram-se os obrigatórios vivas como era habitual nesse tempo. O entusiasmo dos estivadores era total e a adesão ao orador era completa. Mabote gritava "Viva a Mulher!" e centenas de braços bem másculos e vozes ásperas se erguiam concertados num único e vigoroso arremesso. De repente, o general parou e, de cima de um improvisado pódio, contemplou a multidão composta apenas por homens duros, musculados pelo trabalho. O seu olhar era de mandador de almas, habituado à liderança. Foi então que ele deu voz de comando: "Gritem todos comigo, quero que o nosso grito vá bem para além de Maputo." E os homens responderam em coro que sim, que fariam coro com o seu líder. Então, Sebastião Marcos Mabote, levantando os braços a encorajar as massas, iniciou o seguinte mote: "Somos todos mulheres! Somos todos mulheres!" E incentivava, vibrante, para que todos fizessem coro. Um silêncio espantado, uma atrapalhação geral percorreu os estivadores. (...) E insistiu, paciente, até que, passados uns dolorosos minutos, mais e mais vozes másculas proclamassem a sua identidade feminina. Mas ninguém clamou a plenos pulmões. (2009, p.141142)

Stuart Hall postula que o Feminismo também foi uma das causas responsáveis pelo descentramento do sujeito que engendrou nova identidade, um novo lugar social, devido a uma série de rupturas nos discursos do conhecimento moderno. Ou seja, houve mudanças conceituais através das quais o sujeito do Iluminismo, que era visto como tendo uma identidade fixa e estável, foi descentrado, resultando nas identidades abertas, contraditórias, inacabadas, fragmentadas, do sujeito pós-moderno. Essas mudanças conceituais que descentraram o sujeito foram enumeradas por Hall como sendo cinco mais importantes: a revisitação de Marx, na década de 1960; a descoberta do inconsciente por Freud; os trabalhos de Ferdinand Saussure; os estudos de Michel Foucault; e o impacto do Feminismo. No exemplo citado acima, do "Dia da Mulher Moçambicana", pudemos observar a resistência às novas identidades, com um apego à identidade cultural anterior, rejeitando, 
portanto, a identidade do Feminismo e não abdicando de reforçar o seu próprio repertório cultural.

Mia Couto é um grande contador de estórias e essa atividade é dinamizada pelas suas experiências pessoais e profissionais, e sobretudo pelas suas andanças pelo país, como biólogo, que lhe proporcionam muitos contatos com o povo dos lugares e aldeias e suas estórias. Essas estórias são matéria literária por excelência para o escritor. Mesmo nos textos de opinião surge essa veia poética do contador de estórias que Mia Couto encarna, pois são várias as estórias que relata nos seus livros de opinião ou de intervenção, sejam míticas, regionais, do contexto histórico moçambicano etc. A maneira como aborda esse universo de estórias, resgatando-o para dentro de seus textos de opinião referencia a construção do conto ou da crônica, sobretudo desta última.

De modo que, embora o texto de opinião utilize uma linguagem referencial, como definida por Jakobson (2001), sua construção remete e referencia as crônicas, porque é um contar estórias que ilustra a ideia central do texto, e tem um caráter circunstancial e temporal, às vezes até de um fabulismo exemplar, via de regra colocando em tensão o local e o global; a tradição e a modernidade; o real e o transcendente, evidenciando ainda a veia humorística do escritor. Assim, podemos dizer que o conto e a crônica são gêneros que acompanham o caminho da escrita de Mia Couto, municiando-o de temas, personagens e estórias, mesmo quando ele escreve textos de opinião ou de intervenção, utilizando a linguagem referencial.

A pluralidade de identidades para Mia Couto apresenta-se historicizada no texto abaixo:

Nas décadas de 70 e 80 a nossa identidade era simples e homogênea: éramos moçambicanos. Não era pensável, nesse momento, concebermo-nos como macuas, macondes, pretos, mulatos, brancos. De um modo geral, para todos nós, a primeira coisa da nossa identidade é ainda o sermos moçambicanos. Hoje em dia, porém, outras formas de pertença estão-se esboçando. Para muitos de nós estão nascendo outras primeiras identidades. Pode ser uma identidade racial, tribal, 
religiosa. Esse sentimento de pertença pode colidir com isso que chamamos de moçambicanidade. (...) Podemos ser diversas coisas. O erro é quando queremos ser apenas uma. O erro é quando queremos negar que somos diversas coisas ao mesmo tempo. Como dizia Simone de Beauvoir: Não nascemos brancos ou pretos, tornamo-nos, às vezes, brancos e pretos. (COUTO, 2005, p. 87/88).

A verdade é que não existe ninguém que seja "puro". A nossa espécie humana é toda ela feita de mestiçagens. Há milhões de anos que nos andamos cruzando, trocando genes, traficando valores. Não há nesta sala ninguém que não possua uma identidade múltipla e plural. As identidades são como os dedos das mãos. (COUTO, 2005, p. 89).

Ao explicar por que é que as pessoas gostam tanto de Moçambique, Mia Couto pontua a questão da identidade do sujeito pósmoderno de que nos fala Stuart Hall: essa atração por Moçambique "nasce da habilidade em trocarmos cultura e produzirmos mestiçagens. Nasce da capacidade de sermos nós, sendo outros.” (COUTO, 2005, p. 10) E: "Não há nesta sala ninguém que não possua uma identidade múltipla e plural. As identidades são como os dedos das mãos". (idem, p. 89)

\section{Referências bibliográficas}

ANGIUS, Fernanda e ANGIUS, Matteo. O desanoitecer da palavra. Mindelo/Praia: Embaixada de Portugal/Centro Cultural Português, 1998.

CAVACAS, Fernanda. Acrediteísmos. Lisboa: Mar Além, 2001.

COUTO, Mia. Cronicando. Lisboa: Caminho, 1991. . O pais do queixa andar. Maputo: Nadjira, 2003. . Pensatempos - textos de opinião. Lisboa: Caminho, 2005. . E se Obama fosse africano? e outras interinvenções. Lisboa: Caminho, 2009. Pensageiro frequente. Lisboa: Caminho, 2010.

CORTÁZAR, Julio. “Alguns aspectos do conto”. In: Valise de Cronópio. São Paulo: Perspectiva, 1993.

GOTLIB, Nádia Battella. Teoria do conto. São Paulo, 1991. 
HALL, Stuart. A identidade cultural na pós-modernidade. Rio de Janeiro: DP\&A, 2006.

JAKOBSON, Roman. Lingüística e comunicação. São Paulo: Cultrix, 2001.

JOLLES, André. Formas simples. São Paulo: Cultrix, 1996.

MAQUEA, Vera. "Entrevista com Mia Couto." Revista Via Atlântica, São

Paulo, Centro de Cultura e Estudos Portugueses do Departamento de Letras Clássicas e Vernáculas (DLCV) da Faculdade de Filosofia, Letras e Ciências Humanas (FFLCH) da Universidade de São Paulo (USP), n. 8, p. 208, 2005.

REIS, Carlos et al. Dicionário de narratologia. Coimbra: Almedina, 2000. SÁ, Jorge de. A crônica. São Paulo: Ática, 1999.

TODOROV, Tzvetan. Introdução à literatura fantástica. São Paulo: Perspectiva, 1975. 